\title{
Strengths and Limitations of
} Conventional Approaches to the Risk Assessment and Management of EMF Exposure From 5G and B5G Networks

\author{
Haim Mazar ${ }^{1 *}$ and David J. Ball ${ }^{2}$ \\ ${ }^{1}$ ITU Intersector Coordinator on RF-EMF, Modiin, Israel, ${ }^{2}$ Centre for Decision Analysis \& Risk Management, School of Science \\ and Technology, Middlesex University, London, United Kingdom
}

OPEN ACCESS

Edited by:

Adlen Ksentini,

Eurecom, France

Reviewed by:

Kenneth Foster,

University of Pennsylvania,

United States

Martin Röösli,

Swiss Tropical and Public Health Institute (Swiss TPH), Switzerland

${ }^{*}$ Correspondence: Haim Mazar

h.mazar@atdi-group.com

Specialty section:

This article was submitted to

Networks,

a section of the journal Frontiers in Communications and

Networks

Received: 26 June 2021 Accepted: 23 September 2021 Published: 03 November 2021

Citation:

Mazar H and Ball DJ (2021) Strengths and Limitations of Conventional Approaches to the Risk Assessment and Management of EMF Exposure

From $5 G$ and B5G Networks.

Front. Comms. Net 2:731172.

doi: 10.3389/frcmn.2021.731172
This paper describes the current science-based approach to ensuring public safety from RF-EMF base stations. It acknowledges that a degree of public concern persists despite the fact that dose limits are seldom if ever approached in practice. One plausible contributor to the discord is a tendency within parts of academia and by some planning authorities to pursue a technocratic policy approach to siting wherein public concerns are attributed to scientific uncertainty over health risks, whereas the reality is that societal concerns over base stations is broader. Thus, potential mis-framing of the debate as a purely scientific issue leads to inappropriate risk communication exercises which in fact polarise the situation by disenfranchising other potentially legitimate siting concerns. It is recommended that more attention should be paid to the non-health related siting issues, which could be handled by a thoughtful democratic / deliberative process, and that this should not be conflated with the scientific debate over the uncertain and possibly nonexistent risks posed by RF EMF complying with the existing science-based dose limits.

Keywords: base stations, EMF exposure, risk management, risk-framing, public perception

\section{INTRODUCTION}

Wireless communication uses electromagnetic waves in the Radio Frequency (RF) ranges of the spectrum, which are of a much lower frequency compared to ionizing radiation. As such, RF waves do not have enough energy to either break molecular bonds or even cause ionization of atoms in the human body; hence, their classification as Non-Ionizing Radiation (NIR). The heating capabilities of high-level RF-EMF exposure (e.g., from microwave ovens) are well known. The question is whether there are some other enduring health effects at levels of exposure below the International Commission on Non-Ionising Radiation Protection limit (ICNIRP, 2020). While some studies have indicated the possibilities of non-thermal effects in living organisms, these have never been substantiated. For example, a World Health Organization (WHO) Q\&A on 5G mobile networks and health says that "provided that the overall exposure remains below international guidelines, no consequences for public health are anticipated" (ITU/EMF 5G, 2021) and an investigation published by Ofcom in February 2020 reports measurements of EMF exposures close to sixteen 5G-enabled base stations plus other 2G, 3G and 4G locations in ten United Kingdom cities to be a small fraction of the reference levels for public exposure in the ICNIRP Guidelines (ITU/EMF 5G, 2021 p.31).

There is no scientific reason to use different exposure limits in different countries, but there is a tension between policymaking and pressure from public concern in this field. The recent 
Covid-19 pandemic and the related spread of misinformation around $5 \mathrm{G}$ has exacerbated this trend and fueled by social media, has caused incidents in many countries. Updated to April 2021, 332 arson attacks have been reported in 21 countries in the past year ${ }^{1}$. In the context of $5 \mathrm{G}$ infrastructure roll-out and ensuring the safety of existing infrastructure and continuity of services, the incidents pose a significant risk to the deployment and operation of existing and next generation networks, despite the fact that telecommunication networks have played a fundamental part in securing countries' resilience during the COVID crisis.

In this paper we first summarize the regulations and agreed exposure limits for RF sources. We then consider the problem of acceptance from a risk management perspective.

\section{G AND B5G ENGINEERING}

\section{G and B5G Frequencies}

Future mobile communications will deploy $5 \mathrm{G}$ and B5G. ${ }^{2}$ The operating frequencies define the RF human hazards and the EMF exposure limits. Following the 2020 edition of the ITU Radio Regulations (RR), the following frequency bands are identified in the ITU RR, to deploy International Mobile Communications $(\text { IMT) })^{3}$ : 450-470, 470-698, 694/698-960, 1 427-1 518, 1 710-2 025, 2 110-2 200, 2 300-2 400, 2 500-2 690, 3 300-3 400,3 400-3 600, 3 600-3 700 and $4800-4990 \mathrm{MHz} ; 24.25-27.5,37-43.5,45$. 5-47 GHz, 47.2-48.2 and 66-71 GHz . The updated IMT RF band are detailed in Table 3 of ITU-D/Europe (ITU/EMF 5G, 2021).

\section{EMF Updated Exposure Levels From 5G and B5G}

The ICNIRP RF-EMF exposure Guidelines are backed by WHO and constitute the current scientific consensus. "WHO encourages the establishment of exposure limits and other control measures that provide the same or similar level of health protection for all people. It endorses the guidelines of ICNIRP and encourages Member States to adopt these international guidelines". 5 WHO advises that if regulatory authorities react to public pressure by introducing precautionary limits in addition to the already existing science-based limits, they should be aware that this undermines the credibility of the science and exposure limits. ${ }^{6}$

${ }^{1}$ Source: Rowley, J.T. and Knox, N., GSMA (personal communication), 31 July 2021.

${ }^{2}$ Beyond 5G (B5G) will include novel architectural and technology concepts to be linked with $6 \mathrm{G}$.

${ }^{3}$ IMT encompasses IMT-2000, IMT-Advanced and IMT-2020, as specified in Resolution ITU-R 56-2. In this paper 5G and IMT-2020 are interchanged. In this paper IMT is equivalent to $5 \mathrm{G}$.

${ }^{4}$ Frequencies above $24.25 \mathrm{GHz}$ were revised at ITU World Radio Conference (WRC)-19

${ }^{5}$ WHO (2006). Framework for Developing Health-Based EMF Standards. https:// www.who.int/peh-emf/standards/EMF_standards_framework $\% 5$ b $1 \% 5$ d.pdf? $\mathrm{ua}=1$, pp. $7-8$.

${ }^{6} \mathrm{WHO}$ (2002). Establishing a dialogue on risks from electromagnetic fields. Available at https://www.who.int/peh-emf/publications/risk_hand/en/.
WHO acknowledges both the ICNIRP Guidelines and the IEEE standard on its website, but promotes the adoption of ICNIRP Guidelines.

For the $5 \mathrm{G}$ and $\mathrm{B} 5 \mathrm{G}$ frequencies (above $450 \mathrm{MHz}$ ) ICNIRP (2020) power-density exposure levels around base-stations at $450-2000 \mathrm{MHz}$ equal $f_{\mathrm{MHz}} / 40$ for occupational and $f_{\mathrm{MHz}} / 200$ for the general-public. At $2-300 \mathrm{GHz}$ the exposure levels equal $10 \mathrm{~W} / \mathrm{m}^{2}$ for occupational and $2 \mathrm{~W} / \mathrm{m}^{2}$ for general-public. For the $5 \mathrm{G}$ and $\mathrm{B} 5 \mathrm{G}$ frequencies, the ICNIRP and IEEE power-density limits (for whole-body exposure to continuous fields) are identical.

Joshi, (2020) collected data from commercial 5G networks in Australia and the Republic of Korea and found that median device transmit power levels were 1 per cent of the maximum and comparable to $4 \mathrm{G}$ devices; this data is consistent with Ofcom's measurements of EMF exposures.

\section{International Exposure Limits}

The numeric standards for non-ionizing radiation exposure limits are the formal steps taken by governments to limit both the occurrence and consequences of risky exposures. The following text is adopted in 2021 by ITU-D, ITU-T and by the ITU-R Working Parties (WPs) 5A, 5B and 6A: "Administrations are encouraged to follow the ICNIRP Guidelines or IEEE Standard, or limits set by their own experts. The best practice for administrations that choose to use international RF-EMF exposure limits is to limit the exposure levels to the thresholds specified in ICNIRP (2020) Guidelines."

To date, more than 40 countries have put in place national legislative frameworks covering static, low-frequency and highfrequency fields for the general public and workers on either a mandatory or voluntary basis. The details of these different legal frameworks can be accessed from the WHO website. ${ }^{7}$ WHO recommends that "an analysis of the balance between cost and potential hazards is essential", and calls for "strict adherence to existing national or international safety standards". ${ }^{8}$ WHO indicates that the Framework "addresses how to develop science-based quantitative EMF exposure limits" and "is intended for national advisory and/or regulatory bodies that are either developing new standards for EMF or reviewing the basis of their existing standards". ${ }^{9}$ The results of all of the studies and the measurement results further support the advice provided by WHO in relation to base stations and wireless technologies: "Considering the very low exposure levels and research results collected to date, there is no convincing scientific evidence that the weak RF signals from base stations and wireless networks cause adverse health effects". 10

\footnotetext{
${ }^{7}$ WHO. Global Health Observatory data repository. Public health and the environment-EMF: Legislative status-Data by country. filter table $\mid$ reset table Last updated: 2018-06-11 https://apps.who.int/gho/data/node.main. EMFLEGISLATIVESTATUS?lang=en.

${ }^{8}$ WHO. https://www.who.int/peh-emf/about/WhatisEMF/en/index5.html. ${ }^{9}$ WHO. Electromagnetic fields (EMF). Framework for developing health-based EMF standards. https://www.who.int/peh-emf/standards/framework/en/.

${ }^{10} \mathrm{WHO}(2006)$. Electromagnetic fields and public health. Base stations and wireless technologies, Fact Sheet No. 304. https://www.who.int/teams/environmentclimate-change-and-health/radiation-and-health/electromagnetic-fields-andpublic-health.
} 
In February 2021, Australia became one of the first countries to implement the ICNIRP (2020) Guidelines in a national standard. ${ }^{11}$ Uganda also adopted these Guidelines.

\section{The European Legal and Regulatory Framework for Siting Base Stations}

Europe in general ${ }^{12}$ follows the ICNIRP 2020 (and 2020) levels. European regulatory rulings include the EC non-mandatory Council Recommendation 1999/519/EC ${ }^{13}$ which refers to workers' protection and Council Directive 2013/35/EU ${ }^{14}$. In addition there are European standards aimed at measurement of EMF exposures of workers and the public ${ }^{151617}$. The general public limits of ICNIRP $2020^{18}$ (p. 511, Table 7) and the 1999/ 519/EC (Annex III, Table 2) are identical, since ICNIRP (2020) levels have been endorsed by the EC's Scientific Steering Committee. Directive 2013/35/EU Annex 3 Table A3 'Health effects exposure limit values (ELVs) for exposure to EMF from 6 to $300 \mathrm{GHz}$ ' states the power-density, $50 \mathrm{~W} / \mathrm{m}^{-2}$. So the European Legal and regulatory framework for siting $5 \mathrm{G}$ and $\mathrm{B} 5 \mathrm{G}$ base stations relies on ICNIRP (1998 identical to 2020) Guidelines, as endorsed by WHO.

\section{RISK MANAGEMENT \\ Origins of Controversy}

Hesitancy over RF-EMF progress raises economic issues for society. The delay in installing base stations causes harm to users and delays service provision. Studies show that restrictive limits risk doubling the investment required in the order of billions ${ }^{19}$ and blocks the potential to use the spectrum and

\footnotetext{
${ }^{11}$ Australian Radiation Protection and Nuclear Safety Agency (ARPANSA). ARPANSA releases new Australian radio wave safety standard, 25 February 2021. https://www.arpansa.gov.au/news/arpansa-releases-new-australian-radiowave-safety-standard

${ }^{12}$ Despite an EU Recommendation, some EU countries adopt more restrictive thresholds; see WHO 'EMF world wide standards.

${ }^{13}$ Council Recommendation of 12 July 1999 on the limitation of exposure of the general public to electromagnetic fields $(0 \mathrm{~Hz}-300 \mathrm{GHz})$

${ }^{14}$ 'Minimum health and safety requirements regarding the exposure of workers to the risks arising from physical agents (electromagnetic fields)'

${ }^{15}$ 'Product standard to demonstrate the compliance of base station equipment with radiofrequency electromagnetic field exposure limits $(110 \mathrm{MHz}-100 \mathrm{GHz})$, when placed on the market'

${ }^{16 '}$ Measurement and calculation procedures for human exposure to electric, magnetic and electromagnetic fields $(0 \mathrm{~Hz}-300 \mathrm{GHz})$

${ }^{17}$ Procedure for the assessment of the exposure of workers to electromagnetic fields'

${ }^{18}$ For ICNIRP 2020, see Table 9.2: (ICNIRP Table 5) Reference levels for exposure, averaged over 30 minutes and the whole body, to electromagnetic fields from $100 \mathrm{kHz}$ to $300 \mathrm{GHz}$ (unperturbed rms values).

${ }^{19} \mathrm{An}$ example of economic cost for society in Italy, which has 100 times stricter power-density than EMF ICNIRP/IEEE limits, namely $10 \mathrm{~W} / \mathrm{m}^{2}$ at frequencies 2-300 GHz for $30 \mathrm{~min}$ whole-body exposure; see ICNIRP (2020) Table 5 and IEEE (2019) Table 7. Study from 2019 presented at the Italian Parliament argues that avoiding installations of $27,9005 \mathrm{G}$ base-stations approximately requires in total $€ 4$ billion additional costs.
}

address growing traffic requirements. ${ }^{20}$ In principle, the main $5 \mathrm{G}$ and $\mathrm{B} 5 \mathrm{G}$ EMF risk is from handsets, transmitting into our heads.

However, despite the fact that the level of radiation from $5 \mathrm{G}$ roll-out to which the public is exposed is far below accepted exposure limits, resistance to the technology should not come as a surprise as it is well known that people often associate new technologies, of whatever kind, with hazards (see Renn and Benighaus, 2013). As early as the 1960s Starr (1969) noted that the public were willing to accept "voluntary" risks roughly 1,000 times greater than "involuntary" risks Starr (1969), which explains partially why most of the wrath is focused on base stations as opposed to handsets. This bias is reinforced by Starr's other finding that the social acceptance of risk is directly influenced by public awareness of the benefits of a technology. The benefits of handsets are much more apparent than those of base stations.

Starr's research prompted further work on public attitudes to risk by economists, psychologists and sociologists e.g., Tversky and Kahneman (1974), Slovic (2000) and Rayner (1992). A conclusion which emerges is that the kind of technical and quantitative approaches described earlier in this paper provide inadequate reflections of how risk is perceived by individuals. The actual complexity of the situation has been described by Renn and Benighaus (2013).

Within their scheme there are four levels of context, each of which is split into collective and individual manifestations of risk perceptions. At the basic level heuristics or common-sense reasoning strategies are used to form opinions about hazards. As you move up through the scheme cognitive and affective factors (what people believe to be true about a risk), the social and political institutions involved and their perceived trustworthiness (shaped inter alia by the media including social networks), and at the top level, cultural factors, come into play.

With regard to the latter, a particular explanatory theory has been developed by Douglas and Wildavsky (1983) and others, referred to as Cultural Theory. In brief, the theory posits four plausible responses to a hazard depending on which of the following groups one is tied to: hierarchists, egalitarians, individualists or fatalists. The theory argues that each of these worldviews is valid on its own terms, and that each exists because the others exist.

To some extent in line with Cultural Theory's projections, research into public and expert attitudes to EMFs and especially base stations in Germany (Ruddat et al., 2010) identified a minority group of highly concerned individuals which was distinct from a group showing little interest in the health implications of the technology. A third group exhibited concern which was fueled in part by the expectation that scientists should be able to come up with definitive answers about the risks of EMF instead of, merely, guidance, a view predicated on a misunderstanding of the scientific process Mills (2021).

${ }^{20}$ ITU-T K Suppl. 14 (09/2019) The impact of RF-EMF exposure limits stricter than the ICNIRP or IEEE guidelines on $4 G$ and $5 G$ mobile network deployment. 
TABLE 1 | Principles of risk management EISMD (2019).

Guidance for decision makers on using risk concepts in making policy decisions

\begin{tabular}{|c|c|}
\hline Principle 1 & Risk decision making involves more than numbers \\
\hline Principle 2 & The concept of reasonableness must underpin all decisions \\
\hline Principle 3 & There is an inextricable ethical dimension to risk decision making \\
\hline Principle 4 & Risk elimination in public life is rarely sensible and potentially increases danger \\
\hline \multicolumn{2}{|r|}{ Suggestions for improving the quality of risk analysis for public policy making } \\
\hline Principle 5 & Risk communication should be integral to risk management activity \\
\hline Principle 6 & Policy makers should reflect on the appropriateness of attempts to alter people's behaviour \\
\hline Principle 7 & Approaches to risk management must address the issue of trust in institutions \\
\hline Principle 8 & Participative / Deliberative approaches have potential both to promote sound risk management and legitimise decisions \\
\hline \multicolumn{2}{|r|}{ Suggestions for helping the public to make better risk decisions for themselves } \\
\hline Principle 9 & Risk literacy can be improved \\
\hline Principle 10 & The role of vested interests should be made more transparent \\
\hline Principle 11 & $\begin{array}{l}\text { It should be recognised that all approaches to risk are provisional and are based upon currently available evidence and } \\
\text { prevailing social mores }\end{array}$ \\
\hline
\end{tabular}

The experts believed the key to the problem was better communication by mobile phone companies and especially those involved in the siting of base stations. It was considered that there was a breakdown in communication with affected citizens at the siting stage, a view which extended to almost all respondents, expert or lay, and irrespective of whether they were sensitized or indifferent to the issue of EMF.

Research by Hermans (2015) on siting concerns in the Netherlands, however, opened up additional viewpoints. Commencing with a review of the social science literature on mast siting controversies, she found that the academic research focus was largely framed around citizens' understanding of the health risks associated with the technology. This framing, by itself, introduced a clear bias and inexorably led to the conclusion that what was needed was public education via better risk communication.

However, Hermans' research showed that siting controversies arose for a variety of reasons which could not be labelled as "risk issues." For example, concerns included lack of involvement in the siting decision process, landscape pollution, devaluation of property and ecological impacts, and while health concerns were the most often mentioned this appears to have been tied to a belief that such would give legitimacy to the complaint although, in the Dutch case, this misfired because planning authorities were precluded from considering health risks.

Hermans goes on to argue that the choice by the Dutch government to denote mast siting controversies as a scientific matter shifted the problem from the political arena and, in so doing, denied citizens' rights to be engaged in the decision process and reformulated the matter as one of baseless fears over health risks, which were best dealt with via education and risk communication.

\section{Possible Solutions}

As absolute proof about the non-existence of harm from NIR cannot be anticipated regulators are placed in a difficult situation.
To solve this dilemma, some countries have applied the precautionary principle (e.g., Burgess (2004), Rowley (2008) and Wardman and Lofstedt, (2018)), either replacing or augmenting the two-state risk management (threshold) model. This constitutes a trade-off balance between the remaining uncertainty and stricter requirements impacting on resources and quality of service ${ }^{21}$.

As the choice between the two-state risk management model or the precautionary approach has implications for society and the economy, it is important to involve all stakeholders in community awareness activities: government agencies, the private Internet sector, non-governmental organization, community groups and the general public. This need for communication is central to all modern risk management strategies. For example, the European Institute for Science, Media and Democracy identified a set of Principles for the management of risk (EISMD, 2019), which note that risk communication should be an integral part of any risk management activity (see Table 1). Likewise, the International Risk Governance Council sees communication as central (IRGC, 2021). The consequences of not following this route have the potential to create adverse socio-economic consequences for all stakeholders, for example, encouragement of misinformation, delays in upgrading networks and realizing associated benefits, higher costs, environmental impacts and lost opportunities.

However, a further problem is that the debate may have been at least partially mis-framed. In particular, evidence from the Dutch study Hermans (2015) is that the debate over base stations may have been influenced by a sector of the academic community who depicted it as a health risk issue, whose origin was a gap between laypersons' understandings and experts' understandings, for which the remedy was further communication of scientific knowledge. As Hermans says,

\footnotetext{
${ }^{21}$ Mobile Phone Use for Contacting Emergency Services in Life-threatening Circumstances, Wu et al., The Journal of Emergency Medicine, 52(3):291-298. e293, March 2012.
} 


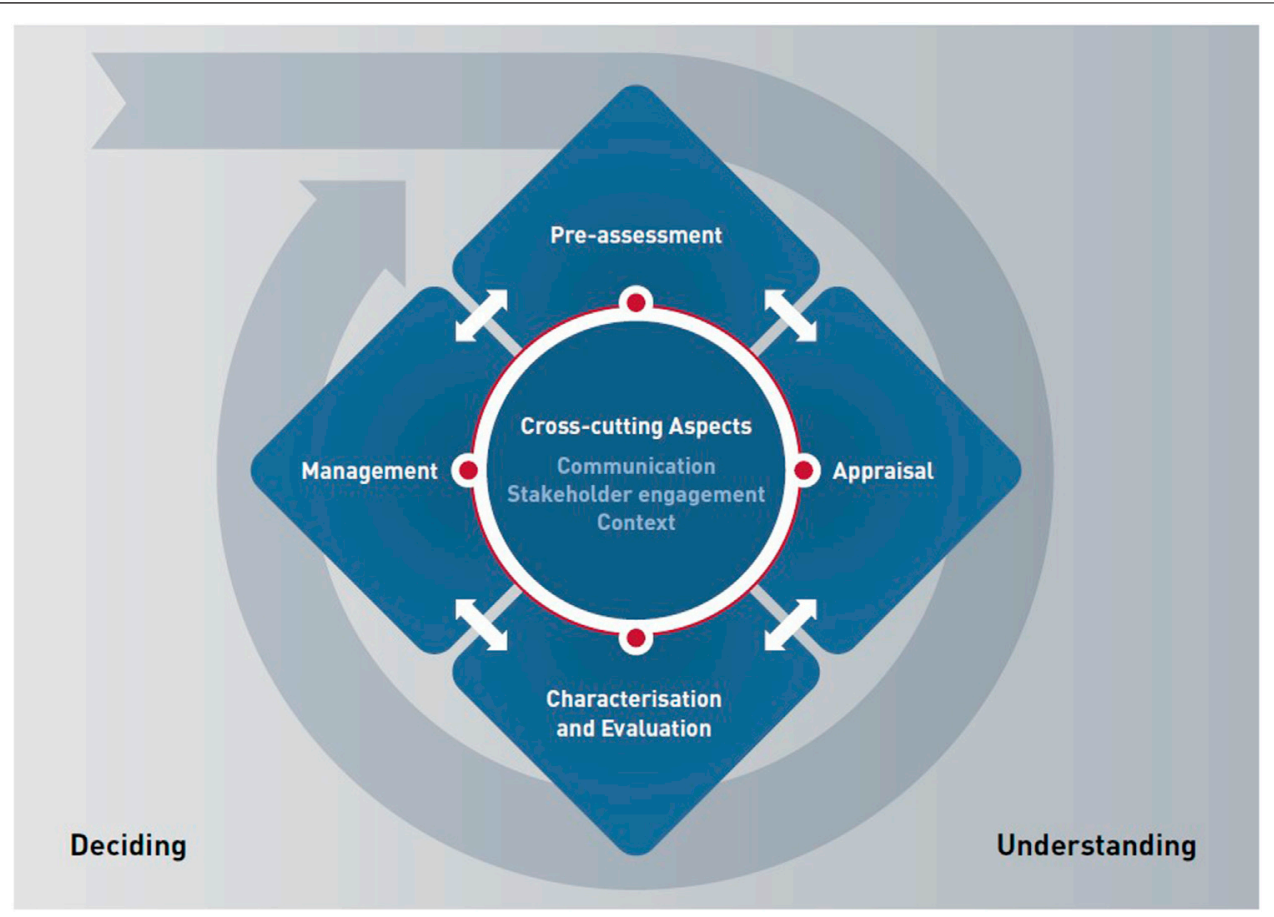

FIGURE 1 | The IRGC risk governance framework IRGC (2021).

quoting Wynne (2008), "It becomes a real problem when scientific knowledge is used as scientism or as public authority knowledge."

The matter of framing is by no means confined to RF-EMF. In an analysis and categorization of environmental concerns in general, and their causes, Ball (2002) identified four main drivers of concern as having substance-derived origins, value-derived origins, processderived origins or stakeholder-derived origins, and twelve subcategories. EMF base stations were listed under substance-derived origins but in the sub-section denoted "the intention impinges adversely on some other aspect of life or the common good which is valued." This is not to say that base station issues aligned solely with that category as values, processes and stakeholders were also implicated to some degree.

The foundational role of risk framing is illustrated by the IRGC (2021) risk governance framework (Figure 1). Framing is the first task listed in the framework, coming under the preassessment stage.

Due to their large benefits, mobile communications will deploy $5 \mathrm{G}$ and $\mathrm{B} 5 \mathrm{G}$ from $470 \mathrm{MHz}$ to $71 \mathrm{GHz}$. The approach now sanctioned is to follow the best scientific advice, and WHO's stress on a need to balance the cost of control and the potential risk is also a feature of current guidelines on risk management. For example, EISMD's Principle 2 is “The concept of reasonableness must underpin all decisions" and Principle 4 is "Risk elimination in public life is rarely sensible and potentially increases danger.'

Also included, however, Principle 1 states that "Risk decision making involves more than numbers" and Principle 8 "Participative / Deliberative approaches have potential to promote sound risk management and legitimize decisions.' This opens the door for a wider consideration of base station impacts including aspects identified by Hermans (2015) such as choice of location, local planning authority decision making, landscape impacts and the justification for the technology. And, as noted by Rowley (2008), the importance of separating health issues from planning policy guidance in a way that is transparent to all stakeholders should be acknowledged.

\section{DATA AVAILABILITY STATEMENT}

The original contributions presented in the study are included in the article/Supplementary Material, further inquiries can be directed to the corresponding author.

\section{AUTHOR CONTRIBUTIONS}

HM conceived the work and suggested the outline of the paper. HM researched and wrote the sections on RF EMF and the dose limits approach to public safety and DB did likewise with respect to the management of risk. Both authors contributed to the entire article and approved the submitted version.

\section{SUPPLEMENTARY MATERIAL}

The Supplementary Material for this article can be found online at: https://www.frontiersin.org/articles/10.3389/frcmn.2021.731172/ full\#supplementary-material 


\section{REFERENCES}

Ball, D. J. (2002). Environmental Risk Assessment and the Intrusion of Bias. Environ. Int. 28, 529-544. doi:10.1016/s0160-4120(02)00061-2

Burgess, A. (2004). Cellular Phones, Public Fears and a Culture of Precaution. New York: Cambridge University Press.

Douglas, M., and Wildavsky, A. (1983). Risk and Culture: An Essay on the Selection of Technical and Environmental Dangers. Los Angeles: University of California Press. Available at: https://www.amazon.com/Risk-Culture-Mary-Douglas/dp/ 0520050630 (Accessed June 6, 2021).

EISMD (2019). Improving Society's Management of Risks: A Statement of Principles. Brussels: EISMD. Available at: https://www.eismd.eu/wpcontent/uploads/2020/02/Capur-Statement-of-Principles.pdf (Accessed May 24, 2025).

Hermans, M. (2015). Engaging with Risk: Citizens, Science and Policy in mobile Phone Mast Siting Controversies. Maastricht, Netherland: Maastricht University, 253. Available at: https://cris.maastrichtuniversity.nl/ws/portalfiles/portal/1100557/guid3c7d0ede-9782-40fb-97c4-47eca54fe7ee-ASSET1.0.pdf (Accessed May, 2021).

ICNIRP (2020). ICNIRP. RF EMF Guidel. 18 (5), 483-524. doi:10.1097/ HP.0000000000001210

IEEE (2019). “C95.1-2019 - IEEE Standard for Safety Levels with Respect to Human Exposure to Electric, Magnetic, and Electromagnetic Fields, $0 \mathrm{~Hz}$ to 300 GHz," in IEEE Std C95.1-2019 (Revision of IEEE Std C95.1-2005/ Incorporates IEEE Std C95.1-2019/Cor 1-2019), 1-312. doi:10.1109/IEEESTD.2019.8859679

IRGC (2021). Risk Governance Framework. Lausanne: IRGC. Available at: https:// irgc.org/risk-governance/irgc-risk-governance-framework/ (Accessed May 24, 2021).

ITU/EMF 5G (2021). Available at: https://www.itu.int/dms_pub/itu-d/opb/pref/ D-PREF-BB.5G_02-2021-PDF-E.pdf (Accessed October 10, 2021).

Joshi, P., Ghasemifard, F., Colombi, D., and Tornevik, C. (2020). Actual Output Power Levels of User Equipment in 5G Commercial Networks and Implications on Realistic RF EMF Exposure Assessment. IEEE Access 8, 204068-204075. doi:10.1109/access.2020.3036977 Available at: https://ieeexplore.ieee.org/ stamp/stamp.jsp?arnumber=9252895 (Accessed June 6, 2021).

Mills, M. J. (2021). "Reframing the Narrative of Victimhood," in The Role of Judgment and Deliberation in Science-Based Policy. Centre for the Study of the Administrative State. Editor C. W. 21-16, 21-38. doi:10.1007/978-3-030-752828_3 Available at: https://administrativestate.gmu.edu/wp-content/uploads/ sites/29/2021/02/Mills-the-Role-of-Judgment-and-Deliberation-in-ScienceBased-Policy.pdf (Accessed May 23, 2021).
Rayner, S. (1992). "Cultural Theory and Risk Analysis," in Social Theories of Risk. Editors S. Krimsky and D. Golding (Westport: Praeger), 83-115.

Renn, O., and Benighaus, C. (2013). Perception of Technological Risk: Insights from Research and Lessons for Risk Communication and Management. J. Risk Res. 16 (3-4), 293-313. doi:10.1080/13669877.2012.729522

Rowley, J. (2008). Good Practice in Regulatory Approaches for mobile Communications and Health. Revue Roumaine Des Sci. Tech. 53 (2bis), 65-78.

Ruddat, M., Sautter, A., Renn, O., Pfenning, U., and Ulmer, F. (2010). Communication about a Communication Technology. J. Risk Res. 13 (3), 261-278. doi:10.1080/13669870902899062

Slovic, P. (2000). The Perception of Risk. London: Earthscan.

Starr, C. (1969). Social Benefit versus Technological Risk. Science 165 (3899), 1232-1238. doi:10.1126/science.165.3899.1232

Tversky, A., and Kahneman, D. (1974). Judgment under Uncertainty: Heuristics and Biases. Science 185 (4151), 1124-1131. doi:10.1126/ science.185.4157.1124

Wardman, J. K., and Löfstedt, R. (2018). Anticipating or Accommodating to Public Concern? Risk Amplification and the Politics of Precaution Reexamined. Risk Anal. 38 (9), 1802-1819. doi:10.1111/risa.12997

Wynne, B. (2008). Elephants in the Rooms where Publics Encounter "science"?: A Response to Darrin Durant, "Accounting for Expertise: Wynne and the Autonomy of the Lay Public". Public Underst Sci. 17, 21-33. doi:10.1177/0963662507085162

Conflict of Interest: The authors declare that the research was conducted in the absence of any commercial or financial relationships that could be construed as a potential conflict of interest.

The reviewer MR is currently organizing a Research Topic with one author HM.

Publisher's Note: All claims expressed in this article are solely those of the authors and do not necessarily represent those of their affiliated organizations, or those of the publisher, the editors, and the reviewers. Any product that may be evaluated in this article, or claim that may be made by its manufacturer, is not guaranteed or endorsed by the publisher.

Copyright (C) 2021 Mazar and Ball. This is an open-access article distributed under the terms of the Creative Commons Attribution License (CC BY). The use, distribution or reproduction in other forums is permitted, provided the original author(s) and the copyright owner(s) are credited and that the original publication in this journal is cited, in accordance with accepted academic practice. No use, distribution or reproduction is permitted which does not comply with these terms. 